\title{
POSISI GURU SEBAGAI ORANG TUA DAN MURID SEBAGAI ANAK MENURUT PERSPEKTIF AL-QUR'AN
}

\author{
Muhammad Abdul Malik \\ Prodi Pendidikan Guru Madrasah Ibtidaiyah \\ Pascasarjana Universitas Islam Negeri Sunan Kalijaga \\ Jl. Marsda Adisucipto Yogyakarta, Indonesia \\ e-mail: abdulmaleekmuhammad@gmail.com \\ Website: https://jurnal.uin-antasari.ac.id/index.php/adzka \\ Received: Juni 2019; Accepted: Juni 2019; Published: Juni 2019
}

\begin{abstract}
The aim of the reasearch is describing how the good relationship between teachers and students, based on the verses about the realionship of parents with the childern and the verses about the good manner to the prophet. This research was qualitative by using descriptive analysis through several Quranic interpretation literature as the main foundation and as the secondary source from other litarature related to the topic of discussion. Based on the research, it was found that: teachers' attitude to the students was (1) calling the students with dear calls (2) giving positive advice actively in a good way, and students' attitude to the teacher were (1) respecting the teacher which bringing the prophetic role, as muallim (2) do not raise the voice in front of teacher (3) thanking to the teacher for the kindness and knowledge (4) do not say innapropriate or yell to the teacher (5) get along and call the teacher politely. This reseach hoped can help in achieving the better goal of education and can make teacher and students respect each other for the achievement of national education goals.
\end{abstract}

Keywords: relationship; teacher; student; Quran

\begin{abstract}
ABSTRAK
Penelitian ini bertujuan untuk menggambarkan bagaimana hubungan antara guru dan murid yang seharusnya, berdasarkan ayat-ayat yang membicarakan hubungan orang tua dengan anak dan ayat-ayat yang membicarakan tentang adab terhadap nabi. Penelitian ini merupakan penelitian kualitatif dengan menggunakan analisis deskriptif dengan landasan utama menggunakan beberapa literatur tafsir Alquran dan sebagai sumber sekunder dari literatur lain yang berhubungan dengan topik pembahasan. Adapun sikap yang harus dilakukan guru terhadap murid adalah (1) memanggil murid denan panggilan kasih sayang, panggilan yang disenangi oleh murid (2) aktif memberikan nasihat yang positif dengan lemah lembut, dengan cara yang baik. Sedangkan bagaimana seorang murid bersikap terhadap gurunya adalah (1) menghormati gurunya dengan sebenar-benarnya karena guru juga membawa peran kenabian, yaitu sebagai muallim (2) jangan meninggikan suara di depan guru (3) banyak berterimakasih kepada guru atas jasa dan ilmu yang telah diberikan (4) tidak berkata yang tidak pantas atau membentak guru (5) bergaul dan memanggil guru dengan lembut. Diharapkan penelitian ini bisa membantu mewujudkan dunia pendidikan yang lebih baik, yang membuat guru dan murid saling menghormati demi tercapainya tujuan pendidikan nasional.
\end{abstract}

Kata kunci: hubungan; guru; murid; Al-quran 


\section{PENDAHULUAN}

Akhir-akhir ini dunia pendidikan di Indonesia ramai dengan cukup banyaknya kasus kekerasan dalam dunia pendidikan yang melibatkan guru dan murid yang kemudian mencuat di televisi dan berbagai media lainnya, terlebih sangat ramai di media sosial. Ada seorang murid yang memukul gurunya, ada juga murid yang menantang gurunya berkelahi, bahkan ada juga yang lapor ke orang tuanya kemudian si murid dan orang tuanya memukuli gurunya di sekolah. Adapula kejadian sebaliknya, guru terlalu keras dalam mendisiplinkan murid sehingga memukul murid sampai terluka. Hal ini tentunya sangat memprihatinkan, bisa jadi kejadian ini hanya beberapa kejadian yang terungkap ke permukaan diantara banyaknya kejadian-kejadian yang tidak ter-expose. Bukankah seharusnya murid harus menghormati guru, guru menyayangi dan membina murid dengan tujuan untuk menjadikan murid memiliki kepribadian yang baik dan cerdas, sedangkan orangtua murid harus bekerjasama dengan baik bersama guru untuk mewujudkan tujuan mulia tersebut.

Pada dasarnya proses belajar mengajar bukan hanya proses mentransfer ilmu pengetahuan (transfer of knowledge) tetapi juga mentransfer kepribadian yang baik (transfer of character), mentransfer akhlakul karimah, baik itu melalui lisan maupun tingkah laku. Di titik ini perlu kiranya ditegaskan peran dan posisi yang seharusnya antara murid dan guru menurut Islam, dengan menggali ajaran yang terdapat dalam Alqur'an dan hadits. Agar di kemudian hari kejadian seperti itu tidak terulang kembali.

Dalam sebuah hadits Rasullulah pernah bersabda:

$$
\text { “آباؤك ثلاثة: أبوك الذى ولدك, و الذى زوّجك ابنتَه, و الذى علّمك وهو أفضلهم” }
$$

Artinya: "Ayahmu ada tiga, ayah biologismu, ayah mertuamu dan ayah yang mengajarkanmu ilmu pengetahuan, dan ialah yang paling utama".

Dalam hadits tersebut Rasulullah menjelaskan bahwa ayah seorang manusia itu ada tiga, yaitu ayah secara biologis, kedua ayah mertua, ketiga ayah yang mengajarkannya ilmu pengetahuan. Rasulullah mengatakan bahwa yang mengajarkanmu ilmu pengetahuanlah yang paling utama diantara yang lain (Zein bin Smith: 2005)

Dengan landasan hadits tersebut, dalam artikel ini penulis akan menelaah ayat-ayat yang berbicara tentang hubungan orang tua dan anak kemudian memposisikan guru sebagai orang tua dan murid sebagai anak, serta menggunakan ayat-ayat Alqur'an yang berbicara mengenai hubungan antara orang tua dan anak untuk mengetahui peran guru sebagai orang tua dan murid sebagai anak, dengan tujuan agar setiap guru dan murid dapat memahami perannya masing-masing sehingga proses belajar mengajar dapat berjalan dengan baik dan tidak ada kesalahpahaman yang berujung pada kekerasan.

\section{METODE PENELITIAN}

Penelitian ini menggunakan metode kualitatif dengan kajian dokumen. Dokumen yang digunakan dalam penelitian ini berupa berbagai macam tafsir Al-Quran. Dalam penelitian ini menggunakan analisis deskriptif berdasarkan literatur-literatur yang membicarakan masalah tentang posisi guru dan murid sebagai hubungan orang tua dan anak. Pada penelitian ini yang dikaji berupa ayat-ayat yang membicarakan hubungan orang tua dan anak dalam Al-Quran dan ayat yang bercerita tentang etika sahabat terhadap Nabi Muhammad.

\section{HASIL PENELITIAN DAN PEMBAHASAN \\ Sikap Guru Terhadap Murid}

Dalam surah Luqman ayat 13 sampai 19 Allah bercerita mengenai hubungan seorang ayah dan anak, yaitu Luqman dan anaknya, Ibnu Katsir (2005: 336) menyebutkan silsilah Luqman adalah Luqman bin Anqa' bin Sadun, sedangkan nama anaknya adalah Tsaran. 
Dalam ayat ini Alqur'an telah memberikan pelajaran dan petunjuk dari kisah nyata seorang Luqman yang dikenal sebagai ahli hikmah, seorang yang dekat dengan Allah dalam mendidik anaknya. Surah Luqman adalah surah makkiyyah, yaitu surah yang turun pada waktu periode Makkah, sebab turunnya surah ini adalah ketika bangsa Quraisy bertanya kepada Nabi Muhammad mengenai kisah Luqman dan anaknya, tentang bakti anaknya kepada kedua orang tuanya, maka turunlah surah tesebut. (Wahbah Zuhaili, 2011: 135)

Di dalam ayat ke-13, 16 dan 17 di atas Luqman memanggil anaknya dengan kalimat "yaa bunayya", di dalam bahasa Arab kalimat seperti itu disebut dengan kalimat tashgir (Bahjat, 2006: 8:18) yang tujuannya adalah memperhalus, memperkecil, kalau dalam konteks waktu adalah hampir atau mendekati. Dalam konteks kalimat "yaa bunayya" di atas artinya adalah penggilan yang halus, lembut penuh kasih sayang. Total ada enam kali penggunaan kata 'yaa bunayya" di dalam Alqur'an, tiga di dalam surah Luqman, satu dalam surah Hud ayat 42, satu dalam surah Yusuf ayat 5, dan satu lainnya dalam surah as-Shaaffat ayat 102. (Fuad, 2002: 308)

Penggunaan kata panggilan kepada anak "ya bunayya" dalam surah Luqman adalah ketika Luqman memanggil anaknya, di dalam surah Hud ketika Nabi Nuh memanggil anaknya, di dalam surah Yusuf ketika Ya'qub memanggil Yusuf anaknya dan di dalam surah as-Shaaffat ketika Ibrahim memanggil anaknya. Dari penggunaan kata "ya bunayya" untuk memanggil seorang anak tersebut, Allah mencontohkan secara langsung dalam ayat-ayat tersebut melalui perantara para Nabi-Nya.

Ketika kita memposisikan guru sebagai orang tua, maka dari ayat tersebut bisa diambil pelajaran bahwa seorang guru selayaknya memanggil murid-muridnya dengan panggilan yang penuh kasih sayang, barangkali kalimat tersebut kalau diterjemahkan kedalam bahasa Indonesia artinya adalah "ananda" sebagaimana panggilan anak kepada ayahnya, yaitu "ayahanda". Guru juga bisa memanggil murid dengan panggilan lain yang kemungkinan disukai oleh murid-muridnya. Dengan panggilan yang baik dan penuh kasih sayang maka akan terbangun ikatan emosional yang bagus, saling hormat dan juga menumbuhkan semangat murid dalam mengikuti pelajaran dan kegiatan lainnya di sekolah. Tentunya ini akan membuat murid aktif dan berprestasi serta memiliki sikap dan mental yang baik.

Dalam ayat-ayat selanjutnya Luqman memberikan beberapa nasihat kepada anaknya, yaitu peringatan bahwa Allah akan membalas semua amal baik dan buruk sekecil apapun itu, menyuruh untuk selalu mendirikan shalat, menyuruh untuk melakukan amar ma'ruf nahi munkar, bersabar atas musibah yang menimpa, menasihati agar tidak sombong dan angkuh, menyuruh berjalan secara perlahan ${ }^{2}$, dan merendahkan suara ${ }^{3}$. Nasihat Luqman kepada anaknya tersebut sebagai isyarat agar orang tua di sekolah, yaitu guru agar selalu aktif dalam memberikan nasihat kepada anak muridnya, terutama menekankan nasihat-nasihat yang disebutkan dalam ayat 16 sampai 19 dalam surah Luqman di atas. Ini juga berlaku ketika anak berbuat kesalahan, guru menegur dan memberi nasihat yang baik dengan lemah lembut.

Dalam konteks dunia pendidikan zaman sekarang ini maka para guru juga dituntut untuk aktif memberi motivasi kepada anak didiknya, agar semangat dalam mengikuti pelajaran di sekolah dan semangat dalam mengejar apa yang ia cita-citakan, karena tidak jarang ada murid yang kurang semangat dalam mengikuti pelajaran di sekolah, membolos, malas-malasan dan perilaku negatif lainnya yang menghambat perkembangan murid.

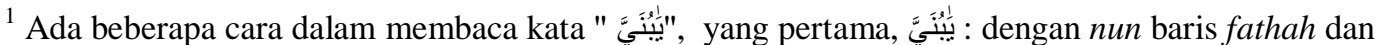
huruf ya ber-tasydid baris fathah adalah qiraat Hafs. Kedua, يُئنيْيْ : dengan nun baris fathah dan huruf ya sukun tanpa tasydid adalah qiraat Ibnu Katsir. Ketiga, : يُيُنيّي : dengan nun baris fathah dan huruf ya ber-tasydid baris kasrah adalah qiraat selain mereka berdua. (Wahbah Zuhaili: 153).

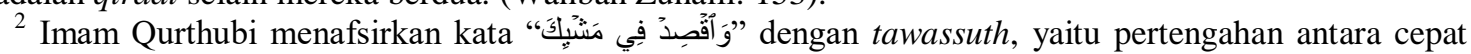
dan lambat (Qurthubi, 2014:48).

${ }^{3}$ Yaitu berbicara dengan suara yang sedang, sebagaimana riwayat dari Yazid bin Abu Habib (Thobari, 2005: 216).
}

Al-Adzka: Vol. 9, No. 1, Juni 2019 


\section{Sikap Murid Terhadap Guru}

Allah subhanahu wa ta'ala befirman dalam surah al-Baqarah ayat 151:

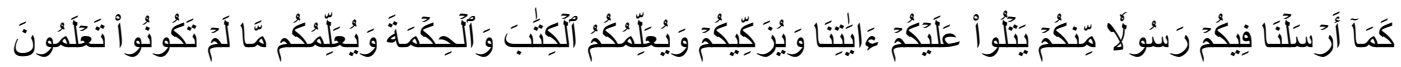

Artinya: "Sebagaimana (Kami telah menyempurnakan nikmat Kami kepadamu) Kami telah mengutus kepadamu Rasul diantara kamu yang membacakan ayat-ayat Kami kepada kamu dan mensucikan kamu dan mengajarkan kepadamu al-Kitab dan Al-Hikmah, serta mengajarkan kepada kamu apa yang belum kamu ketahui".

Dalam ayat tersebut, Allah menjelaskan beberapa peran Muhammad sebagai Rasulullah, pertama; sebagai orang yang membacakan ayat-ayat Allah, kedua; sebagai orang yang mensucikan umatnya, ketiga; sebagai orang yang mengajarkan al-Kitab, hikmah dan hal-hal lainnya yang belum diketahui oleh umatnya.

Minimal, seorang guru memiliki satu peran dari peran-peran seorang rasul di atas, yaitu sebagai muallim yang mengajarkan apa-apa yang belum diketahui atau yang belum dimengerti oleh murid-muridnya. Tidaklah berlebihan kalau dikatakan bahwa guru, ulama merupakan pewaris Nabi, karena mereka menjalankan tugas yang dibawa oleh seorang Nabi. Karena itu, seharusnya seorang murid menghormati guru karena guru adalah orang yang mengemban salah satu peran yang dilakukan oleh Nabi. Salah satu adab yang harus dimiliki seorang murid terhadap gurunya adalah seperti yang terdapat dalam firman Allah surah alHujurat ayat 2 berikut:

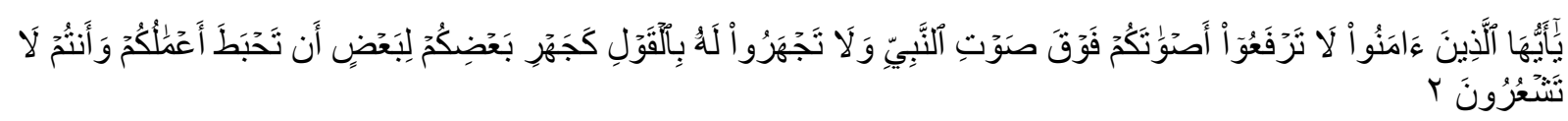

Artinya: "Hai orang-orang yang beriman, janganlah kamu meninggikan suaramu melebihi suara Nabi, dan janganlah kamu berkata kepadanya dengan suara yang keras, sebagaimana kerasnya suara sebagian kamu terhadap sebagian yang lain, supaya tidak terhapus (pahala) amalanmu, sedangkan kamu tidak menyadari”.

Menurut Ibnu Katsir (2005: 365) dalam riwayat yang disebutkan oleh Imam bukhari, sababun nuzul ayat tersebut terkait dengan dua orang sahabat nabi yang paling utama, yaitu Abu Bakar dan Umar. Pada suatu waktu, Abu Bakar dan Umar meninggikan suara mereka di samping Nabi Muhammad ketika datang rombongan Bani Tamim, salah satu dari mereka (Abu Bakar dan Umar) menunjuk Aqra' bin Habis, dan yang lainnya menunjuk laki-laki yang lain, maka berkatalah Abu Bakar kepad Umar: "Engkau tidak menginginkan apapun selain berselisih denganku!", Umar menjawab: "Aku bukannya hendak menyelisihimu!" maka meninggilah suara mereka berdua dan turunlah ayat tersebut.

Dalam ayat tersebut Allah melarang sahabat untuk meninggikan suara di hadapan Nabi, berbicara dengan suara yang tinggi sebagamana yang biasa dilakukan dengan sesama. Nabi Muhammad adalah seorang guru, guru bagi para sahabat, guru bagi umat Islam. Adab yang bisa dipelajari oleh seorang murid dari ayat tersebut adalah agar tidak meninggikan suara ketika berbicara dengan teman ketika ada guru, terlebih lagi berbicara terhadap guru dengan suara yang tinggi.

Dalam surah Luqman Allah mewasiatkan untuk berterimakasih kepada kedua orang tuanya yang telah bersusah payah mengandung dan membesarkannya. Dalam konteks hubungan guru dan murid, ini berarti seorang murid harus banyak berterima kasih kepada gurunya, karena gurunya telah banyak berjasa dalam membimbing, mengajarkan akhlak yang baik dan mengajarinya ilmu pengetahuan.

Selanjutnya ada prinsip yang harus dipegang teguh oleh anak atau murid ketika ada perintah atau ada paksaan dari gurunya. Jika perintah atau paksaan itu menyuruh untuk syirik 
kepada Allah atau melakukan sesuatu yang berupa maksiat, maka ia harus menolaknya dengan tegas, namun setelah itu ia juga harus tetap memperlakukan gurunya dengan baik. " لا طاعة لمخلوق في معصية الخالق" : artinya: "Tidak ada ketaatan bagi manusia jika itu untuk maksiat kepada Allah"

Di ayat lain Allah juga memerintahkan agar seorang anak (murid) berbuat baik kepada orang tuanya, dan dalam konteks penelitian ini maka berarti guru adalah orang tuanya, ketika mereka mulai beranjak tua jangan pernah berkata "uff" (cih, ah atau kata-kata yang menunjukkan kekesalan lainnya), jangan membentak dan selalu mengucapkan kata-kata yang baik. Merendahkan diri di hadapan mereka dan selalu mendoakan mereka. Terkadang seringkali murid lupa mendoakan guru-guru yang telah banyak berjasa dalam membimbing dan memberikan ilmu pengetahuan yang bermanfaat bagi kehidupan mereka.

Kita dapat melihat contoh yang baik tentang hal ini dalam sebuah cerita bahwa Imam Ahmad bin Hanbal selalu mendoakan gurunya Imam Syafi'i setiap hari ketika shalat selama 30 tahun. Ahmad bin Hanbal berkata " Inilah yang kalian lihat dan dapatkan secara keseluruhan dari Syafi'i. Selama 30 tahun aku selalu berdo'a kepada Allah untuk Syafi'i dan memohonkan ampunan untuknya". Murid Imam Syafi'i yang lain juga medo'akan Imam Syafi'i, yaitu Yahya bin Sa'id al-Qaththan ia berkata, "Dalam shalatku selama empat tahun ini aku selalu berdo'a kepada Allah untuk Syafi'i" dan ia juga berkata "aku selalu mendoakan Syafi'i secara khusus." Abdurrahman bin Mahdi juga berkata "setiap melaksanakan shalat aku selalu berdo'a untuk Syafii'i.'(Suwaidan: 2007)

Dalam Alqur'an Surah Al Isra ayat 23-24 Allah berfirman:

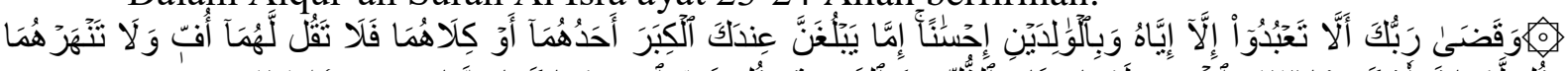

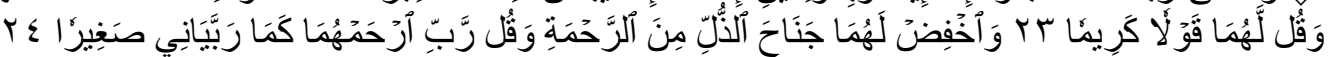

Artinya: "Dan Tuhanmu telah memerintahkan supaya kamu jangan menyembah selain Dia dan hendaklah kamu berbuat baik pada ibu bapakmu dengan sebaik-baiknya. Jika salah seorang di antara keduanya atau kedua-duanya sampai berumur lanjut dalam pemeliharaanmu, maka sekali-kali janganlah kamu mengatakan kepada keduanya perkataan "ah" dan janganlah kamu membentak mereka dan ucapkanlah kepada mereka perkataan yang mulia".

"Dan rendahkanlah dirimu terhadap mereka berdua dengan penuh kesayangan dan ucapkanlah: "Wahai Tuhanku, kasihilah mereka keduanya, sebagaimana mereka berdua telah mendidik aku waktu kecil".

Sedangkan panggilan "halus" anak kepada orang tua di dalam Alqur'an adalah "يَآََبَتِ (yaa abati) sebagaimana yang terdapat dalam surah as-Shaaffat ayat 102:

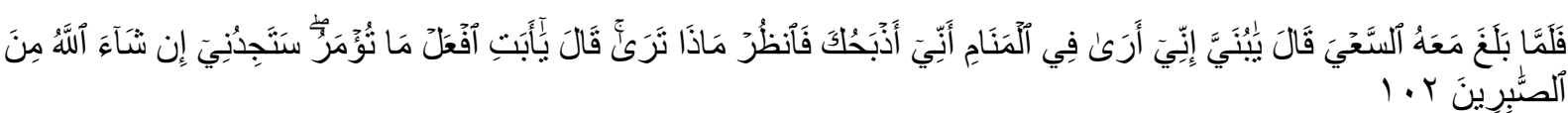

Artinya: "Maka tatkala anak itu sampai (pada umur sanggup) berusaha bersama-sama Ibrahim, Ibrahim berkata: "Hai anakku sesungguhnya aku melihat dalam mimpi bahwa aku menyembelihmu. Maka fikirkanlah apa pendapatmu!" Ia menjawab: "Hai bapakku, kerjakanlah apa yang diperintahkan kepadamu; insya Allah kamu akan mendapatiku termasuk orang-orang yang sabar".

Penggunaan kata 'yaa abati" sebagai panggilan seorang anak kepada ayahnya ada delapan kali dalam Alqur'an, dua dalam surah Yusuf ayat 4 dan 100, empat kali dalam surah Maryam ayat 42, 43, 44 dan 45, satu kali dalam surat al-Qashash ayat 26, yang terakhir satu kali dalam surat as-Shaaffat di atas, ayat 102 (Fuad, 2002: 33).

Di dalam surah Yusuf ayat 4 dan 100, penggunaan kata panggilan kepada ayah " $y a$ abati" adalah ketika Yusuf memanggil ayahnya, yaitu Ya'qub, tiga kali di dalam surah Maryam adalah ketika Ibrahim memanggil ayahnya, di dalam surah al-Qashash adalah ketika puteri Nabi Syuaib memanggil ayahnya, dan kemudian di dalam surah as-Shaaffat ketika 
Isma'il memanggil ayahnya. Penggunaan kata "yaa abati" atau panggilan yang halus untuk ayah dalam beberapa ayat diatas mengajarkan adab bagaimana seorang murid memanggil gurunya dengan panggilan yang halus dan penuh hormat. Di Martapura, Kalimantan Selatan ada sorang ulama besar yang bernama KH. Zaini Abdul Ghani biasa dipanggil "abah guru" oleh para muridnya sebagai panggilan hormat yang tinggi dan penuh kasih sayang terhadap sang guru.

\section{PENUTUP}

Allah telah memberikan petunjuk dan pelajaran dengan ayat-ayatnya dalam Alqur'an mengenai sikap guru terhadap murid dan sebaliknya, bagaimana seharusnya sikap murid terhadap guru, seperti melalui nasihat Luqman kepada anaknya, kisah Ibrahim dan Isma'il, surah al-Isra ayat 23-24, contoh langsung dari kehidupan nabi Muhammad dan para sahabat, serta contoh-contoh lain yang berhamburan dari kisah-kisah para tabi'in, tabi'ut tabi'in dan para ulama yang mana mereka sangat menghormati gurunya dan gurunya pun memperlakukan muridnya dengan baik, seperti kisah Imam Ahmad bin Hanbal dan Imam Syafi'i.

Dengan memahami ayat-ayat Allah di atas dan kisah-kisah inspiratif mengenai hubungan antara guru dan murid yang baik, semoga kedepannya tidak akan terjadi lagi kekerasan yang melibatkan guru dan murid dalam dunia pendidikan di Indonesia demi terlaksananya dunia pendidikan yang harmonis, saling sinergi antara guru dan murid serta tercapainya tujuan pendidikan nasional yang sama-sama kita dambakan.

\section{DAFTAR PUSTAKA}

Al-Qurthubi, Muhammad bin Ahmad. (2014). Al-Jami'Li Ahkam Alqur'an. Beirut: Dar alKutub al-Ilmiyah.

Asy-Syikhaly, Bahjat Abdul Wahid. (2006). I'rab Alqur'an al-Karim: Lughatan wa I'jazan wa Balaghatan wa Tafsiran bi Ijaz. Beirut: Dar al-Fikr.

At-Thobari, Muhammad bin Jarir. (2005). Jami' al-Bayan fi Ta'wil Alqur'an. Beirut: Dar alKutub al-Ilmiyah.

Az-Zuhaili, Wahbah. (2011). At-Tafsir al-Munir: fi al-Aqidah wa asy-Syari'ah wa al-Manhaj. Damaskus: Dar al-Fikr.

Ba'alawi, Zein bin Smith. (2005). Al Manhaj as Sawi. Tarim: Dar al-Ilm wad Da'wah.

Baqi, Muhammad Fuad Abdul. (2002). al-Mu'jam al-Mufahras li Alfazh Alqur'an al-Karim. Beirut: Dar al-Ma'rifah.

Katsir, Isma'il bin Umar bin. (2005). Tafsir Alqur'an al-Azhim. Riyadh: Dar Thabaqah.

Suwaidan, Tariq. (2007). Biografi Imam Syafi'i: Kisah Perjalanan dan Pelajaran Hidup Sang Mujtahid. Jakarta: Penerbit Zaman. 